\title{
A case of erb-duchenne palsy in a man aged 24
}

\begin{abstract}
Erb's palsy or Erb-Duchenne palsy is a paralysis of the arm caused by traction injury to the upper trunk of the brachial plexus. It is commonly, but not exclusively, caused by dystocia, an abnormal or difficult childbirth or labour. It can occur if the infant's head and neck are pulled towards the side at the same time as the shoulders pass through the birth canal. Erb's palsy in adults isf comparatively uncommon; it may follow trauma to the head and shoulder causing violently stretching of the nerves of the upper trunk of the brachial plexus. The anatomical basis of the clinical presentations has not been described in the literature, thus clinical diagnosis is difficult. In the current paper, case of Erb's palsy in an adult is presented. It has been demonstrated that, suprascapular nerve $(\mathrm{C} 5,6)$, musculocutaneous nerve $(\mathrm{C} 5,6,7)$ and axillary nerve $(\mathrm{C} 5,6)$ are the branches of the brachial plexus involved in Erb's palsy. The skeletal muscles innervated by these nerves are severely affected compared to the cutaneous nerves that supply general sensation to the skin. The Erb's palsy in adult is very uncommon, the knowledge of this anatomy of the clinical presentation is important in the diagnosis and proper management of the condition.
\end{abstract}

Volume 3 Issue $6-2017$

\author{
Osabutey CK \\ Department of Anatomy, Kwame Nkrumah University of \\ Science and Technology, Ghana
}

\begin{abstract}
Correspondence: Osabutey CK, Department of Anatomy, School of Medical Sciences, Kwame Nkrumah University of Science and Technology, Kumasi, Ashanti Region, Ghana, Tel
\end{abstract} +233245992850, Email casmielosabutey@hotmail.com

Received: January 02, 2017 | Published: June 20, 2017

Keywords: erb's palsy, erb-duchenne palsy, dystocia, brachial plexus, upper trunk

\section{Introduction}

Erb's palsy or Erb-Duchenne palsy is a paralysis of the arm caused by injury to the upper trunk of the brachial plexus. ${ }^{1}$ The brachial plexus comprising the ventral rami of spinal nerves (C5-T1). C5 and C6 join to form the upper trunk, $\mathrm{C} 7$ travels alone as the middle trunk, and $\mathrm{C} 8$-T1 joins as the lower trunk. Each trunk divides into anterior and posterior divisions to create the cords, which then subdivide further into branches that supply the muscles of the arm. ${ }^{2,3}$

The most common cause of Erb's palsy is dystocia, an abnormal or difficult childbirth or labour. ${ }^{4-6}$ It can occur if the infant's head and neck are pulled towards the side at the same time as the shoulders pass through the birth canal. ${ }^{7}$ The condition can also be caused by excessive pulling on the shoulders during a cephalic presentation, or by pressure on the raised arms during a breech delivery. ${ }^{8}$ Erb's palsy can also affect neonates with clavicular fracture unrelated to dystocia.

Erb's palsy in an adult is extremely rare following trauma to the head and shoulder, which causes the nerves of the plexus to violently stretch, with the upper trunk of the brachial plexus sustaining the greatest injury. ${ }^{10,11}$ Injury may also occur as a result of direct violence, ${ }^{12,13}$ including gunshot wounds ${ }^{14-16}$ and traction on the arm, or attempting to reduce shoulder joint dislocation. ${ }^{17}$ The level of damage to the constituent nerves is related to the severity of the paralysis. ${ }^{18}$

However, the anatomical basis of the clinical presentations has not been described in the literature. Clinical diagnosis is therefore difficult. In the current paper, case of Erb's palsy in an adult is presented and the anatomical bases of the clinical presentations are discussed.

\section{Case presentation}

In the case presented here, a young man aged 24 was hit on the left shoulder by a falling tree branch about three months ago. He was seen during a routine out-patient consultation in Millennium Charity Hospital in Atwima Kwawuma District in Ashanti Region of Ghana. Immediately after the injury, he reported and got treated in several Health Centers and Hospitals without any improvement. His main complaints were inability to abduct the left shoulder, inability to flex the left elbow and numbness on the lateral aspect of the left forearm. Previous investigation revealed no fracture of the bones of the shoulder girdle. Following clinical examination, a written consent from both the patient and the father were sought before photographs were taken for presentation.

\section{Discussion of the anatomy}

Erb-Duchenne palsy presents as a lower motor syndrome associated with sensibility disturbance. The classical sign of Erb's palsy is showed in the photograph (Figure 1)-the arm to hang limply from the shoulder. This sign is the result of damage to the biceps muscle causing loss of power of flexion of the elbow.

The most commonly involved nerves are the suprascapular nerve, musculocutaneous nerve and the axillary nerve. ${ }^{1,2}$ Figure 2 is a drawing to illustrate the parts of the brachial plexus involved in Erb's palsy.

The suprascapular nerve $(\mathrm{C} 5,6)$ is a direct branch of the upper trunk. It supplies the supraspinatus and infraspinatus muscles. These muscles are part of the rotator cuff muscles that are lateral rotators of the arm. The patient's arm is medially rotated because these muscles are paralyzed.

The musculocutaneous nerve $(\mathrm{C} 5,6,7)$ is a branch of the lateral cord. It supplies muscular branches to all the muscles of the flexor compartment of the arm namely coracobrachialis, brachial is and biceps brachii and continues as lateral cutaneous nerve of the forearm innervating the skin overlying the lateral aspect of the forearm. These muscles are flexors of the forearm at the elbow; the biceps brachii is also a powerful supinator of the forearm. The patient's elbow is extended and partly pronated because, these muscles are paralyzed; the triceps brachii and the pronators over activity is keeping the elbow in extension and pronation.

The axillary nerve $(\mathrm{C} 5,6)$ is a branch of the posterior cord. It supplies muscular branches to the deltoid and teres minor muscles and continues as the upper lateral cutaneous nerve of the arm innervating 
the skin overlying the deltoid muscle. The signs of Erb's Palsy in adult include loss of sensation in the arm and paralysis and atrophy of the deltoid, biceps, and brachialis muscles as has been described in obstetrical Erb's palsy in babies. ${ }^{18}$ "The position of the limb, under such conditions, is characteristic: the arm hangs by the side and is rotated medially; the forearm is extended and pronated. The arm cannot be raised from the side; all power of flexion of the elbow is lost, as is also supination of the forearm" as it has been described in obstetrical Erb's palsy in babies. ${ }^{18}$ The resulting biceps damage is the main cause of this classic physical position commonly called "waiter's tip."

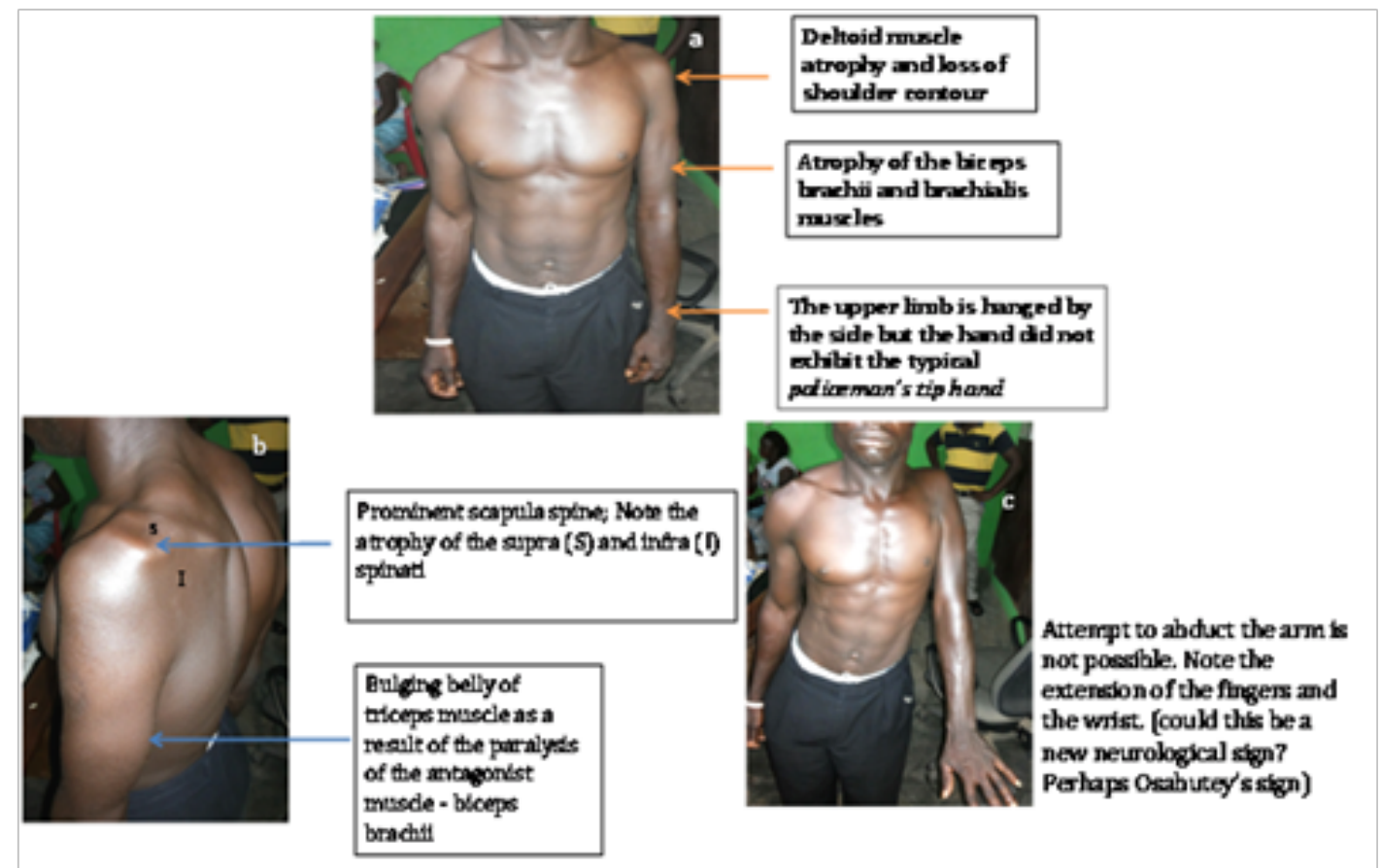

Figure I Annotated photograph of a 24years old man with Erb's palsy about three month ago.

Note that in Figure IA, the elbow fully extended and medially rotated due to weakness of the lateral rotators.

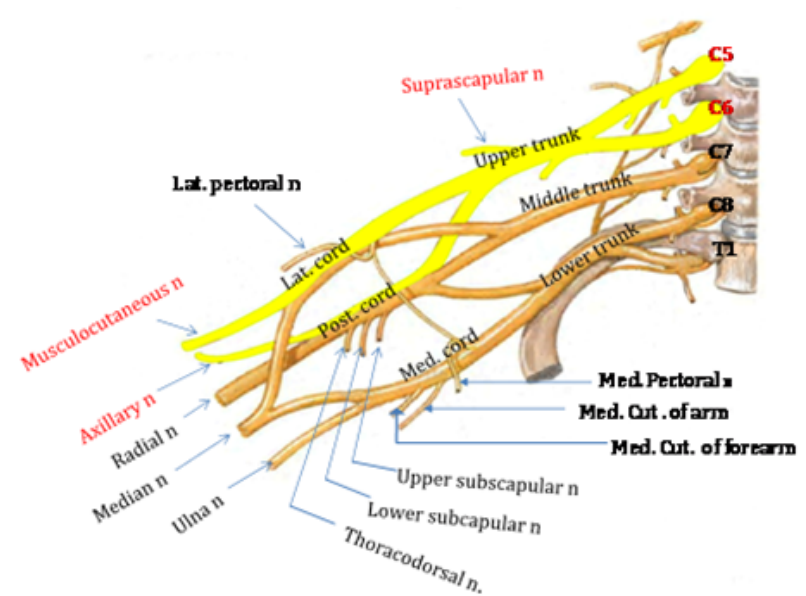

Figure $2 \mathrm{~A}$ drawing to illustrate the parts of the brachial plexus involved in Erb -Duchanne's palsy. The affected nerves are indicated yellow: C5 and C6 roots, upper trunk.

Lat, lateral; Med, medial, Post, posterior; n, nerve

\section{Conclusion}

In conclusion, knowledge of Erb's palsy in an adult and the understanding of the current anatomy of the condition is important in the clinical diagnosis and proper management.

\section{Acknowledgements \\ None.}

\section{Conflict of interest}

Author declares that there is no conflict of interest.

\section{References}

1. Erb WS. Ueber Eine Eigent humliche Localisation Von Lahmengenim Plexus Brachialis. Verhandl D Naturhist Med. 1874;2:130-137.

2. Bannister LH, Berry MM, Collins P, et al. Gray's Anatomy, anatomical basis of anatomy and surgery. 38th ed. London: Churchill Livingstone; 1999. p. 1266-1267.

3. Tortora GJ, Anagnostakos NP. Principles of Anatomy and Physiology. 6th ed. New York: Harper \& Row; 1990. p. 370-374.

4. Allen RH, Gurewitsch ED. Temporary Erb-Duchenne palsy without shoulder dystocia or traction to the fetal head. Obstet Gynecol. 2005;105(5 Pt 2):1210-1212.

5. Christoffersson M, Kannisto P, Rydhstroem H, et al. Shoulder dystocia and brachial plexus injury: a case-control study. Acta Obstet Gynecol Scand. 2003;82(2):147-151.

6. Gherman RB, Ouzounian JG, Miller DA, et al. Spontaneous vaginal delivery: a risk factor for Erb"s palsy? Am J Obstet Gynecol. 1998;178(3):423-427.

7. Weizsaecker K, Deaver JE, Cohen WR. Labour characteristics and neonatal Erb's palsy. BJOG. 2007;114(8):1003-1009. 
8. Eng GD, Binder H, Getson P, et al. Obstetrical brachial plexus palsy (OBPP) outcome with conservative management. Muscle Nerve. 1996;19(7):884-891.

9. Peleg D, Hasnin J, Shalev E. Fractured clavicle and Erb's palsy unrelated to birth trauma. Am J Obstet Gynecol. 1997;177(5):1038-1040.

10. Rankin JJ. Adult traumatic brachial plexus injury. Clin Radio. 2004;59(9):767-774.

11. Thatte MR, Babhulkar S, Hiremath A. Brachial plexus injury in adults: Diagnosis and surgical treatment strategies. Ann Indian Acad Neurol. 2013;16(1):26-33.

12. Lain TM. The military brace syndrome. A report of sixteen cases of Erb's palsy occurring in military cadets. J Bone Joint Surg Am. 1969;51(3):557-560.

13. Wilson WJ. Brachial plexus palsy in basic trainees. Mil Med. 1987;152(10):519-522.
14. Brooks DM. Open wounds to the brachial plexus. Spec Rep Ser Med Res Counc (GB). 1954;282:418-429.

15. Kim DH, Murovic JA, Tiel RL, et al. Penetrating injuries due to gunshot wounds involving the brachial plexus. Neurosurg Focus. 2004;16(5):E3.

16. Kline D. Civilian gunshot wounds to the brachial plexus. J Neurosurg. 1989;70(2):166-174.

17. Shears E, Sunderamoorthy D, Ali SA. Brachial plexus injury after anterior shoulder dislocation: a case report. Acta Orthop Belg. 2005;71(4):489-490.

18. Fisher DM, Borschel GH, Curtis CG, et al. Evaluation of elbow flexion as a predictor of outcome in obstetrical brachial plexus palsy. Plast Reconstr Surg. 2007;120(6):1585-1590. 